698

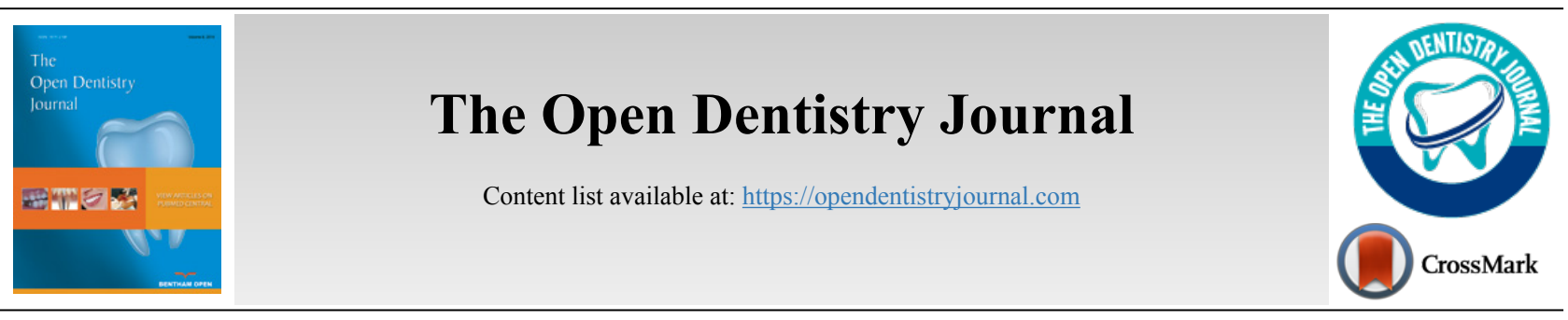

CASE REPORT

\title{
Management of the Two Dental Developmental Anomalies in Two Maxillary Incisors for Improved Esthetic Appearance: A Case Report
}

\author{
Thiyezen A. AlDhelai ${ }^{1,2, *}$ \\ ${ }^{I}$ Department of Orthodontics and Pediatric Dentistry, Faculty of Dentistry, Qassim University, Buraydah, Saudi Arabia \\ ${ }^{2}$ Department of Orthodontics and Pediatric Dentistry, Faculty of Dentistry, Ibb University, Ibb, Yemen
}

\begin{abstract}
:
Introduction:

The presence of a developmental dental anomaly in maxillary incisors usually affects esthetic appearance. Therefore, gemination and supernumerary teeth are considered anomalies and need a careful and comprehensive diagnosis and treatment.

Case Description:

This clinical report presents a 10-year-old girl complaining of the esthetic appearance of her anterior maxillary teeth. Clinical and radiographical examinations revealed a maxillary geminated permanent left central incisor and a supplemental supernumerary permanent right lateral incisor. The treatment has been performed in different stages, including preventive, conservative, surgical, and orthodontic treatments. Thus, the large geminated incisor has been restored to its normal shape, and the problem of anterior incisor crowding resolved through alignment.

Conclusion:

Dental anomalies in the anterior segment are common and need time during treatment. Selective grinding for the large geminated incisor and the extraction of the supplemental tooth followed by orthodontic treatment may be the right decisions that a dental practitioner may consider during the
\end{abstract} management of such cases.

Keywords: Gemination, Maxillary incisors, Selective grinding, Supplemental, Supernumerary, Dental anomalies.

\begin{tabular}{|l|l|l|l|}
\hline Article History & Received: August 08, 2021 & Revised: September 28, 2021 & Accepted: October 26, 2021
\end{tabular}

\section{INTRODUCTION}

The appearance and alignment of the anterior teeth represent the cornerstone of facial esthetics. Different studies demonstrate that tooth with poor esthetic affects the appearance of individuals [1]. Dental anomalies appear to negatively affect the appearance of the teeth and the general esthetics of a person. According to the World Health Organization (WHO) classification of tooth development and eruption disorders in the International Classification of Disease version 10 (WHOICD-10), different types of anomalies in terms of teeth number, size, form, and structure formation are present. The abnormalities in tooth size and form, which include concrescence, fusion, gemination, and macrodontia, are listed in section no. (K00.2-K14) [2].

\footnotetext{
* Address correspondence to this author at the Department of Orthodontic and Pediatric Dentistry, College of Dentistry, Qassim University, Buraydah, Saudi Arabia; Tel: +966581168075; E-mail: t.aldhelai@qu.edu.sa
}

Gemination was first described by Tannenbaum and Falling in 1963 as the development of two identical teeth from one follicle, leading to the separation of those teeth into either a large bifid crown with a single root or two completely separated teeth. Sometimes, a notch on the incisal surface of the enlarged crown is present [3,4]. Geminated tooth is counted as one tooth. Thus, the total number of teeth in the dental arch does not change [5]. Gemination is different from fusion, which refers to the merging of two separate teeth germs before calcification, leading to a large crown with two distinct roots [6]. Usually, a tooth is missing in the total number in the dental arch. The only exception is union occurring between a normal tooth and a supernumerary tooth. In this situation, the differentiation between gemination and fusion is difficult [7, 8]. The occurrence of gemination and fusion in the anterior maxillary region can cause crowding, rotation, and bad teeth alignment, and influence the appearance of the teeth and their associated periodontal tissues [9]. 
Supernumerary teeth are another developmental anomaly. An extra tooth/teeth surpass the normal dental primary/permeant count with similar or different normal tooth morphology [10]. Supernumerary teeth are included in WHOICD-10 with section no. (K00.1-K14) [2]. In accordance with their shape, supernumerary teeth can be classified into conical type, tuberculate type, supplemental teeth, and odontomas. The supplemental tooth is a supernumerary tooth with the same morphological appearance as the normal tooth $[10,11]$. Supplemental teeth may lead to an ectopic eruption of adjacent teeth or overcrowding, and other dental problems [11, 12].

Developmental anomaly is considered as one of the leading causes of dental malocclusion that constitutes a remarkable health problem worldwide [13]. This report aims to present a girl's case with two different dental anomalies in two different maxillary incisors. The present report shows how these anomalies affect her aesthetic appearance and the efforts made to regain her normal appearance.

\section{CASE DESCRIPTION}

\subsection{Patient Information}

A healthy 10-year-old Egyptian girl visited the pediatric dentistry clinic at the Qassim University, Saudi Arabia, with her mother on $1 / 2 / 2019$. The girl complained that she looked ugly because of one of her anterior teeth and the poor arrangement of the other anterior teeth.

The child was a full-term baby. She did not have a previous problem either in her medical or family history. Her dental history revealed no past intervention and bad dental habits.

\subsection{Clinical Findings}

Upon clinical and radiographical examinations, dental findings were as follows: a unilateral, large, wide permanent maxillary left central incisor crown with a notch in the incisal edge. Radiographically, a single large pulp chamber and a single incomplete root formation were observed. All of these data came under the gemination dental anomaly. Moreover, two identical permanent maxillary lateral incisors were present on the right side, indicating a supplemental supernumerary lateral incisor. Teeth were vital, and overcrowding in the maxillary anterior teeth region was observed (Fig. 1a). Besides, the girl was still in mixed dentition and suffered from multiple dental caries due to poor oral hygiene.

\subsection{Diagnostic Assessment}

The clinical intraoral examination, including inspection, palpation, vitality testing, and periodontal probing, was performed for the upper anterior teeth and surrounding tissues to determine the child's oral hygiene. Moreover, the radiographic examination included a panorama and two periapical radiographs to confirm the presence of geminated and supplemental teeth (Figs. $\mathbf{2 a}-\mathbf{b}$ and $\mathbf{3 a} \mathbf{a}-\mathbf{b}$ ).
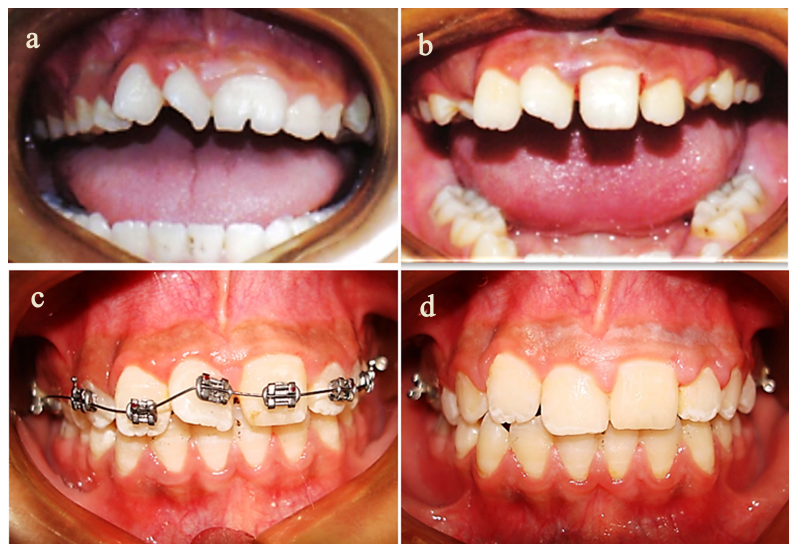

Fig. (1). Intraoral photographs: (a) pretreatment intraoral photograph showing the maxillary geminated central incisor and maxillary supplemental supernumerary lateral incisor, (b) intraoral photograph following the reduction of geminated crown and extraction of the supernumerary tooth, (c) intraoral photograph showing the orthodontic treatment stage, and (d) intraoral photograph following the orthodontic appliance debonding.

\subsection{Therapeutic Intervention}

The treatment plan was set into three phases considering the child's age, dentition stage, type of tooth abnormality, and esthetic demands of the mother and the girl. The phases were preventive, conservative, and surgical, and finally, the orthodontic stage. After the preventive measures were applied and dental caries was managed, the supplemental supernumerary maxillary lateral incisor (tooth far from the midline) was extracted to obtain enough space for the rotated permanent maxillary right central and lateral incisors. The management of the geminated central incisor was started by the selective grinding procedure through a periodic reduction of the crown from the mesial and distal sides and not more than 1 $\mathrm{mm}$ by using a thin tapered fissure bur (Drendel + Zweiling Diamant GmbH, Lemgo, Germany) with a water-cooled, highspeed handpiece. The reduction side was protected by applying a fluoride varnish (Duraflor ${ }^{\circledR}$ Fluoride varnish, AMD Medicom Inc, Montreal, Canada). This reduction was continued every month and stopped in the fifth month. A periapical radiograph was taken at every visit to assess the condition of the pulp during reduction. Then, a composite filling for the notched groove was applied to improve the appearance of this incisor (Quadrant Universal LC, Cavex Holland BV, RW Haarlem, The Netherlands) (Figs. 1 and 2b-d). The Nance space maintainer appliance was applied to maintain the space during the transition from mixed dentition to permanent dentition.

After consultation with an orthodontist, a fixed orthodontic appliance was bonded to the maxillary arch (Fig. 1c). The transpalatal arch was replaced using the Nance appliance to maximize the anchorage. Leveling and alignment were done, then a power chin on heavy rectangular stainless-steel wire was used to close the spaces between teeth. The orthodontic appliance and the transpalatal arch were debonded by finishing the orthodontic treatment, and a fixed maxillary retainer was applied. The orthodontic treatment took about nine months. 


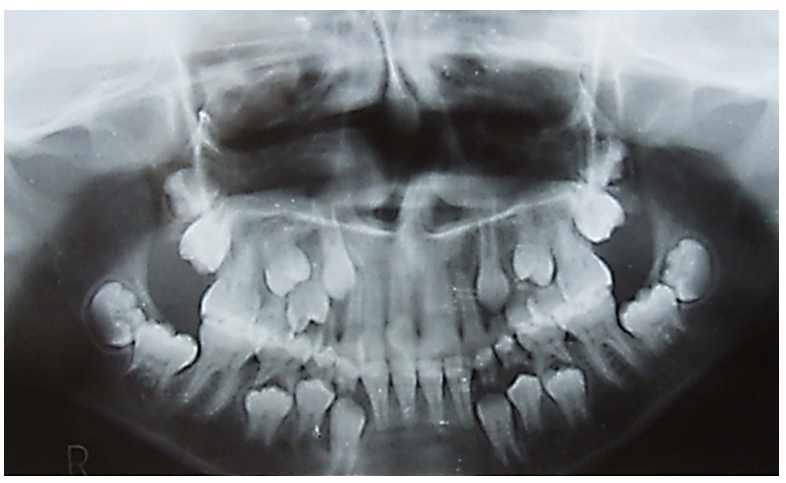

Fig. (2). Pretreatment panoramic radiograph showing the maxillary left geminated central incisor and the right supplemental supernumerary tooth.

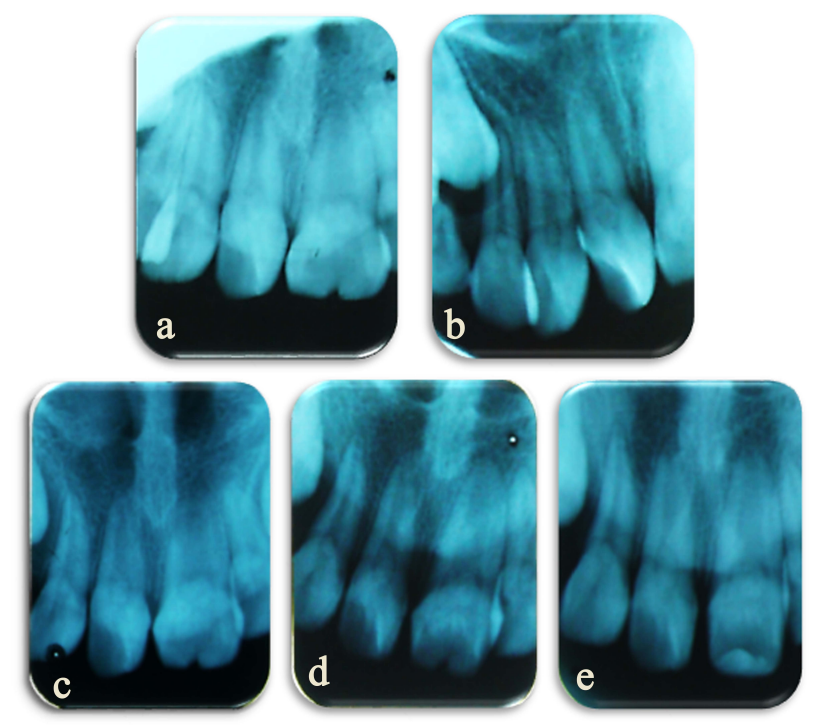

Fig. (3). Periapical radiographs: (a) pretreatment radiograph showing the maxillary geminated central incisor, (b) pretreatment radiograph showing the maxillary supplemental supernumerary lateral incisor, (c) d) follow-up periapical radiograph showing the geminated incisor reduction, and (e) post-treatment periapical radiograph following the final crown reduction and composite filling for the incisal notch.

\subsection{Follow-up and Outcomes}

In terms of the esthetic appearance and function of the anterior teeth, the girl and her mother were satisfied with the final result (Fig. 1d). The girl was instructed to improve her oral hygiene, and the importance of maintaining a fixed maxillary retainer forever was explained. Furthermore, the treatment lasted more than 1.5 years and the follow-up has been conducted at another year. The long-term follow-up was planned with her mother. Veneering or crowning for the treated geminated tooth is needed after the child reaches 18 years old to improve the esthetic appearance.

\section{RESULTS AND DISCUSSION}

The present geminated teeth situation is in agreement with the previous literature, with the tooth being the permanent maxillary left central incisor $[6,14,15]$. Likewise, the supplemental tooth is a permanent maxillary right lateral incisor $[11,16]$. Besides, both teeth are in a unilateral position in the anterior maxillary region $[17,18]$. The prevalence of supernumerary teeth is $1.5 \%-3.5 \%$ in the permanent teeth representing a considerably higher value than germination [11, 19].

The diagnosis for this case is made on the basis of the history taken and adequate clinical and radiographical examinations. Clinically, the maxillary teeth count is increased despite the left questionable tooth being diagnosed as a gemination. This count increases because of two maxillary right lateral incisors, leading to abnormal teeth count $[4,17]$. A radiographical examination by using a periapical radiograph in the incisor region besides a panorama radiograph has been considered as one of the conforming and effective methods to detect gemination and supernumerary teeth $[7,20,21]$.

The management of this case has been divided into three stages. Different strategies are available in the literature to manage a large geminated tooth depending on its morphological changes and types. These strategies include conservative/endodontic treatment, surgical intervention, orthodontic treatment, and prosthodontic treatment [8, 22 - 26]. In accordance with the size, shape of the crown, and pulp morphology of this geminated tooth, the treatment used is the selective grinding technique with conservative filling for the incisal notch. Grinding is done gradually every month to avoid pulpal exposure through the reparative dentin formation. The reduced side is covered by topical fluoride varnish at each visit to protect the exposed enamel from sensitivity. Then, a composite filling is used to restore the incisal notch to gain a natural appearance $[8,27-29]$. A supplemental maxillary right lateral incisor is extracted, which is considered the acceptable treatment method. Considering that we have two identical maxillary lateral incisors, the tooth in the less favorable position for orthodontic treatment is chosen. Therefore, the incisor far from the midline is extracted for more space to facilitate orthodontic teeth movement during space closing. The orthodontist supports this decision [11]. In the present case, we have a supplemental erupted tooth with complete root development, and overcrowding is observed in the anterior teeth segment. Thus, the decision and time to extract that tooth are right considering that the girl is ten years old [30, 31]. Finally, orthodontic management is considered one of the essential ways of management for such conditions $[8,22,27$, 32].

In the current case, the etiology of gemination and the supplemental tooth is unclear because of no clinical, family, or dental history listed regarding the girl. Moreover, an association between these geminated and supplemental incisors has appeared, providing evidence that they have a common etiological reason [33].

\section{CONCLUSION}

Multiple dental anomalies in the anterior segment, like gemination, are uncommon and need time during treatment. In this report, early diagnosis and patient compliance are some of the cornerstones in gemination management. Selective grinding techniques seem to be minimally invasive methods for managing large geminated incisors without endangered pulp. 
Besides, the extraction of the supplemental incisor in the less favorable position and orthodontic treatment are essential techniques to eliminate crowding in the maxillary anterior region and improve the esthetic appearance.

\section{ETHICS APPROVAL AND CONSENT TO PARTICIPATE}

Not applicable.

\section{HUMAN AND ANIMAL RIGHTS}

No animals were used in this research. All human research procedures were followed in accordance with the ethical standards of the committee responsible for human experimentation (institutional and national), and with the Helsinki Declaration of 1975, as revised in 2013.

\section{CONSENT FOR PUBLICATION}

The treatment plan was discussed with the girl and her mother, and permission and written informed consent were obtained from the girl's mother before treatment.

\section{STANDARDS FOR REPORTING}

CARE guidelines and methodology have been followed.

\section{AVAILABILITY OF DATA AND MATERIALS}

All the data of this case are available upon request.

\section{FUNDING}

None.

\section{CONFLICT OF INTEREST}

The author declares no conflict of interest, financial or otherwise.

\section{ACKNOWLEDGEMENTS}

The author sincerely thanks Dr. Bara Ali Hanandeh (BDS, MDSc, MFD RCSI), an orthodontic specialist, for his help and guidance during the case planning and treatment in the orthodontic stage.

\section{REFERENCES}

[1] Shaw WC, Rees G, Dawe M, Charles CR. The influence of dentofacial appearance on the social attractiveness of young adults. Am J Orthod 1985; 87(1): 21-6.

[http://dx.doi.org/10.1016/0002-9416(85)90170-8] [PMID: 3855347]

[2] International statistical classification of diseases and related health problems (ICD-10). World Health Organization 2010.https://icd.who.int/browse10/2010/en\#/K00-K14

[3] Tannenbaum KA, Alling EE. Anomalous tooth development. Case reports of gemination and twinning. Oral Surg Oral Med Oral Pathol 1963; $16: 883-7$

[http://dx.doi.org/10.1016/0030-4220(63)90326-8] [PMID: 13984880]

[4] Neville BW, Damm DD, Allen CM, Chi AC. Oral and maxillofacial pathology. 4th ed. London, United Kingdom: Elsevier Health Sciences 2015.

[5] Schuurs AH, van Loveren C. Double teeth: Review of the literature. ASDC J Dent Child 2000; 67(5): 313-25. [PMID: 11068663]

[6] White SC, Pharoah MJ. Oral radiology: Principles and interpretation. 7th ed. St. Louis: Mosby, Inc. 2013.

[7] Shrivastava S, Tijare M, Singh S. Fusion/double teeth. J Indian Acad Oral Med Radiol 2011; 23(5): 468-70. [http://dx.doi.org/10.5005/jp-journals-10011-1200]

[8] Finkelstein T, Shapira Y, Bechor N, Shpack N. Fused and geminated permanent maxillary central incisors: Prevalence, treatment options, and outcome in orthodontic patients. J Dent Child (Chic) 2015; 82(3): 147-52.

[PMID: 26731250]

[9] Shrestha A, Marla V, Shrestha S, Maharjan IK. Developmental anomalies affecting the morphology of teeth - A review. RSBO 2015; 12(1): $68-78$

[http://dx.doi.org/10.21726/rsbo.v12i1.175]

[10] Garvey MT, Barry HJ, Blake M. Supernumerary teeth--An overview of classification, diagnosis and management. J Can Dent Assoc 1999; 65(11): 612-6.

[PMID: 10658390]

[11] Ata-Ali F, Ata-Ali J, Peñarrocha-Oltra D, Peñarrocha-Diago M. Prevalence, etiology, diagnosis, treatment and complications of supernumerary teeth. J Clin Exp Dent 2014; 6(4): e414-8. [http://dx.doi.org/10.4317/jced.51499] [PMID: 25593666]

[12] Proff P, Fanghanel J, Allegrini Jr S, Bayerlein T, Gedrange T. Problems of supernumerary teeth, hyperdontia or dentes supernumerarii. Annals of Anatomy-Anatomischer Anzeiger 2006; 188(2): 163-9.

[http://dx.doi.org/10.1016/j.aanat.2005.10.005]

[13] Petersen PE. The World Oral Health Report 2003: Continuous improvement of oral health in the 21st century-the approach of the WHO Global Oral Health Programme. Community Dent Oral Epidemiol 2003; 31(Suppl. 1): 3-23.

[http://dx.doi.org/10.1046/j..2003.com122.x] [PMID: 15015736]

[14] O Carroll MK. Fusion and gemination in alternate dentitions. Oral Surg Oral Med Oral Pathol 1990; 69(5): 655.

[http://dx.doi.org/10.1016/0030-4220(90)90252-N] [PMID: 2333217]

[15] Altug-Atac AT, Erdem D. Prevalence and distribution of dental anomalies in orthodontic patients. Am J Orthod Dentofacial Orthop 2007; 131(4): 510-4.

[http://dx.doi.org/10.1016/j.ajodo.2005.06.027] [PMID: 17418718]

[16] Pippi R. Odontomas and supernumerary teeth: Is there a common origin? Int J Med Sci 2014; 11(12): 1282-97.

[http://dx.doi.org/10.7150/ijms.10501] [PMID: 25419174]

[17] Duncan WK, Helpin ML. Bilateral fusion and gemination: A literature analysis and case report. Oral Surg Oral Med Oral Pathol 1987; 64(1): 82-7.

[http://dx.doi.org/10.1016/0030-4220(87)90121-6] [PMID: 3475662]

[18] Anthonappa RP, Omer RS, King NM. Characteristics of 283 supernumerary teeth in southern Chinese children. Oral Surg Oral Med Oral Pathol Oral Radiol Endod 2008; 105(6): e48-54.

[http://dx.doi.org/10.1016/j.tripleo.2008.01.035] [PMID: 18417392]

[19] Burhan AS, Nawaya FR, Arabi Katbi ME, Al-Jawabra AS. Prevalence of supernumerary teeth in a nonsyndromic Syrian sample. J Egypt Public Health Assoc 2015; 90(4): 146-9.

[http://dx.doi.org/10.1097/01.EPX.0000475614.20865.db] [PMID: 26854894]

[20] Finkelstein T, Shapira Y, Bechor N, Shpack N. Surgical and orthodontic treatment of a fused maxillary central incisor and supernumerary tooth. J Clin Orthod 2014; 48(10): 654-8. [PMID: 25416343]

[21] Anthonappa RP, King NM, Rabie AB. Diagnostic tools used to predict the prevalence of supernumerary teeth: A meta-analysis. Dentomaxillofac Radiol 2012; 41(6): 444-9.

[http://dx.doi.org/10.1259/dmfr/19442214] [PMID: 22752325]

[22] Tarım Ertaş E, Yırcalı Atıcı M, Arslan H, Yaşa B, Ertaş H. Endodontic treatment and esthetic management of a geminated central incisor bearing a talon cusp. Case Rep Dent 2014; 2014123681

[http://dx.doi.org/10.1155/2014/123681] [PMID: 24715989]

[23] Oelgiesser D, Zyc R, Evron D, Kaplansky G, Levin L. Treatment of a fused/geminated tooth: A multidisciplinary conservative approach. Quintessence international (Berlin, Germany : 1985) 2013; 44(7): 531-3.

[24] Türkaslan S, Gökçe HS, Dalkız M. Esthetic rehabilitation of bilateral geminated teeth: A case report. Eur J Dent 2007; 1(3): 188-91. [http://dx.doi.org/10.1055/s-0039-1698337] [PMID: 19212565]

[25] Almoammar K. M Aldrees A, Bawazir O, N Alqutub M Autotransplantation as a treatment modality of macrodontia: A case report. Oral Health Dent Manag 2014; 13: 1081-5.

[26] G S, Jena A. Prevalence and incidence of gemination and fusion in maxillary lateral incisors in odisha population and related case report. J Clin Diagn Res 2013; 7(10): 2326-9.

[PMID: 24298521] 
[27] BE F. Interdisciplinary conservative approach of a geminated tooth. J Dent \& Oral Disord 2016; 2(8): 1042

[28] Segura-Egea JJ, Jimenez-Rubio A, Velasco-Ortega E, Rios-Santos JV. Talon cusp causing occlusal trauma and acute apical periodontitis: Report of a case. Dental traumatology : official publication of International Association for Dental Traumatology 2003; 19(1): 55-9. [http://dx.doi.org/10.1034/j.1600-9657.2003.00110.x]

[29] Sener S, Unlu N, Basciftci FA, Bozdag G. Bilateral geminated teeth with talon cusps: A case report. Eur J Dent 2012; 6(4): 440-4. [http://dx.doi.org/10.1055/s-0039-1698985] [PMID: 23077426]

[30] Rajab LD, Hamdan MA. Supernumerary teeth: Review of the literature and a survey of 152 cases. Int J Paediatr Dent 2002; 12(4): 244-54.

[http://dx.doi.org/10.1046/j.1365-263X.2002.00366.x]

[PMID:
12121534]

[31] Parolia A, Kundabala M, Dahal M, Mohan M, Thomas MS Management of supernumerary teeth. J Conserv Dent 2011; 14(3): $221-4$.

[http://dx.doi.org/10.4103/0972-0707.85791] [PMID: 22025821]

[32] Tuna EB, Yildirim M, Seymen F, Gencay K, Ozgen M. Fused teeth: A review of the treatment options. J Dent Child (Chic) 2009; 76(2): 109-16.

[PMID: 19619423]

[33] Laganà G, Venza N, Borzabadi-Farahani A, Fabi F, Danesi C, Cozza P. Dental anomalies: Prevalence and associations between them in a large sample of non-orthodontic subjects, a cross-sectional study. BMC Oral Health 2017; 17(1): 62.

[http://dx.doi.org/10.1186/s12903-017-0352-y] [PMID: 28284207]

\section{C) 2021 Thiyezen Abdullah AlDhelai}

This is an open access article distributed under the terms of the Creative Commons Attribution 4.0 International Public License (CC-BY 4.0), a copy of which is available at: https://creativecommons.org/licenses/by/4.0/legalcode. This license permits unrestricted use, distribution, and reproduction in any medium, provided the original author and source are credited. 